\title{
Intronic Polymorphisms Affecting Alternative Splicing of Human Dopamine D2 Receptor Are Associated with Cocaine Abuse
}

\author{
Robert A Moyer', Danxin Wang', Audrey C Papp', Ryan M Smith', Linda Duque², Deborah C Mash ${ }^{2}$ \\ and Wolfgang Sadee*,I
}

'Program in Pharmacogenomics, Department of Pharmacology, College of Medicine, The Ohio State University, Columbus, OH, USA;

${ }^{2}$ Departments of Neurology and Molecular and Cellular Pharmacology, University of Miami School of Medicine, Miami, FL, USA

\begin{abstract}
The dopamine receptor D2 (encoded by DRD2) is implicated in susceptibility to mental disorders and cocaine abuse, but mechanisms responsible for this relationship remain uncertain. DRD2 mRNA exists in two main splice isoforms with distinct functions: D2 long (D2L) and D2 short (D2S, lacking exon 6), expressed mainly postsynaptically and presynaptically, respectively. Two intronic single-nucleotide polymorphisms (SNPs rs2283265 (intron 5) and rs 1076560 (intron 6)) in high linkage disequilibrium (LD) with each other have been reported to alter D2S/D2L splicing and several behavioral traits in human subjects, such as memory processing. To assess the role of DRD2 variants in cocaine abuse, we measured levels of D2S and D2L mRNA in human brain autopsy tissues (prefrontal cortex and putamen) obtained from cocaine abusers and controls, and genotyped a panel of DRD2 SNPs ( 119 abusers and 95 controls). Robust effects of rs 2283265 and rs 1076560 on reducing formation of D2S relative to D2L were confirmed. The minor alleles of rs $2283265 /$ rs 1076560 were considerably more frequent in Caucasians (18\%) compared with African Americans (7\%). Also, in Caucasians, rs2283265/rs 1076560 minor alleles were significantly overrepresented in cocaine abusers compared with controls (rs2283265: 25 to $9 \%$, respectively; $p=0.00 \mathrm{I} ; \mathrm{OR}=3.4(\mathrm{I} .7-7.1)$ ). Several SNPs previously implicated in diverse clinical association studies are in high LD with rs2283265/rs 1076560 and could have served as surrogate markers. Our results confirm the role of rs2283265/rs 1076560 in D2 alternative splicing and support a strong role in susceptibility to cocaine abuse.

Neuropsychopharmacology (20II) 36, 753-762; doi:10.1038/npp.2010.208; published online 8 December 2010
\end{abstract}

Keywords: alternative splicing; cocaine; dopamine; DRD2; D2S; human

\section{INTRODUCTION}

The dopamine receptor D2 is a member of the D2-like family of dopamine receptors, which are coupled to $G_{i}$ inhibitory G-proteins and generally reduce formation of intracellular cAMP when activated (Civelli et al, 1993; Strange, 1993). D2 receptors are robustly expressed in the striatum and prefrontal cortex (PFC), areas involved in the primary reinforcing effects of drugs of abuse (Hyman et al, 2006) and cognitive processes (Seamans and Yang, 2004), respectively. The involvement of $\mathrm{D} 2$ receptors with addiction and cognition is well documented. In rodent models, response to drugs of abuse, including cocaine, ethanol,

*Correspondence: Dr W Sadee, Program in Pharmacogenomics, Department of Pharmacology, College of Medicine, The Ohio State University, 5072 Graves Hall, 333 W IOth Avenue, Columbus, OH 43210-1239, USA, Tel: + (6/4) 292 1597, Fax: (6/4) 2927232 , E-mail: wolfgang.sadee@osumc.edu

Received 12 August 2010; revised 18 October 2010; accepted 3 November 2010 nicotine, and morphine, is disrupted by administration of D2 agonists or antagonists, and in transgenic mice lacking D2 (reviewed by Le Foll et al, 2009). In human cocaine abusers, D2 receptor availability and activity in frontal brain regions is reduced, even after months of detoxification (Volkow et al, 1993).

$D R D 2$ has been linked to drug addiction, although associations with specific genetic variants are not always replicable (for recent review, see Le Foll et al, 2009). Association studies have typically focused on markers in protein-coding regions used, in part, for historical reasons, whereas recent studies indicate that regulatory polymorphisms in non-coding regions - most as yet undiscoveredoccur more frequently (Johnson et al, 2005; Rockman and Wray, 2002; Wray, 2007). As functional variants contributing to disease are generally unknown for multigenic non-Mendelian disorders, such as drug addiction, reported associations between the disease and a polymorphism typically rely on marker single-nucleotide polymorphisms (SNPs) in linkage disequilibrium (LD) with the causal 
variant. As allele frequencies and LD patterns may differ across ethnic populations, results obtained using surrogate markers may vary between association studies, underscoring the importance of identifying functional genetic variants in candidate genes.

One important mechanism for modulating D2 signaling is alternative splicing of exon 6, resulting in long (D2L) and short (D2S) isoforms expressed mainly postsynaptically and presynaptically, respectively (Khan et al, 1998). Studies in mice lacking D2L but not D2S have shown that D2S functions primarily as an autoreceptor inhibiting D1 dopamine receptor-mediated functions, whereas postsynaptic D2L receptors can act synergistically with D1 receptors (Usiello et al, 2000). Further studies in mice lacking D2L have revealed altered behavioral responses to morphine (Smith et al, 2002) and psychotic and antipsychotic agents (Xu et al, 2002). In postmortem human striatum and PFC, we have previously characterized two $D R D 2$ intronic SNPs (rs1076560 and rs2283265, referred to hereafter as SNP1 and SNP2, existing in high LD with each other $\left.\left(D^{\prime}=1.0\right)\right)$, which were associated with decreased relative expression of D2S mRNA, and a promoter SNP (rs12364283) associated with enhanced DRD2 mRNA expression (Zhang et al, 2007). In the same study, SNP1/SNP2 also reduced cognitive performance in healthy humans on working memory and attentional control tasks (Zhang et al, 2007). The extensively studied rs1800497 (also known as Taq1A) is unlikely to contribute directly to DRD2 mRNA expression or splicing, but the Taq1A1 allele is in LD with the minor alleles of SNP1/SNP2 $\left(D^{\prime}=0.855\right.$, Zhang et al, 2007), providing a possible mechanistic basis for the numerous clinical associations observed with Taq1A (Munafo et al, 2004, 2007; Zhang et al, 2010).

As a result of the importance of D2 alternative splicing, one goal of this study was to replicate the relationship between SNP1/SNP2 and D2 splicing in a different set of brain tissues. Moreover, we searched for additional genetic variants that could affect D2 splicing. Finally, we assessed the relationship between D2S/L splicing, SNP1/SNP2 genotype, and cocaine abuse status in human brain autopsy $\mathrm{PFC}$ and putamen tissues from chronic cocaine abusers who died from cocaine intoxication, and age-matched drug-free controls. Although we did not identify any additional polymorphisms between exon 5 and 7 affecting D2S/L splicing, we did confirm the role of SNP1/SNP2 in D2S/L splicing and identified both SNPs as potential risk factors for cocaine abuse.

\section{MATERIALS AND METHODS}

\section{Postmortem Human Brain Tissues}

Miami brain bank. PFC (Brodmann's area 46) and putamen tissue samples from 119 cocaine abusers who died from cocaine intoxication and 95 age-matched drug-free controls were provided by the Miami Brain Endowment Bank (University of Miami, Miami, FL). Supplemental brain and blood toxicology and neuropathologic evaluations were done in every case, and most of the drug exposure cases obtained at autopsy came from individuals who had evidence of a number of surrogate measures of chronic cocaine abuse (drug-related pathology, arrest records, and hospital and treatment admissions). Drug-free age-matched control subjects were selected from accidental or cardiac sudden deaths with negative urine screens for all common drugs, and there was no history of psychiatric disorders or licit or illicit drug use before death.

Stanley array collection. DNA extracted from postmortem brain tissues were donated by The Stanley Medical Research Institute's (Chevy Chase, MD) brain collection. We obtained genomic DNA and total RNA extracted from 105 individuals and selected five DNA samples for further analysis based on the results of allelic mRNA ratio analysis of D2S and D2L reported by Zhang et al, 2007.

\section{DNA and RNA Extraction}

DNA and RNA were extracted as described in Zhang et al, 2005. cDNA was synthesized with SuperScript III (Life Technologies, Foster City, CA) using both gene-specific primers and oligo(dT), except for the minigene experiment (see below).

\section{DNA Sequencing}

DNA sequencing of PCR product amplified from genomic DNA was performed with a 3730 DNA analyzer using the BigDye Terminator Cycle Sequencing kit (Life Technologies).

\section{Cell Culture and Minigene Splicing}

Human embryonic kidney (HEK) 293 cells were cultured in DMEM/F12 media containing 10\% FBS and 1\% penicillinstreptomycin under $5 \% \mathrm{CO}_{2}$. We used the Stratagene Quik Change Lightning site-directed mutagenesis kit (Agilent Technologies, Santa Clara, CA) to introduce rs35608204 into a DRD2 minigene consisting of exons 5-7 and introns 5 and 6 in pcDNA3 (Zhang et al, 2007). The constructs were sequenced to confirm the intended genotypes and transfected into HEK 293 cells using Lipofectamine 2000 (Life Technologies). RNA was extracted $24 \mathrm{~h}$ later and cDNA synthesized using only a plasmid-specific primer, SP6, to avoid synthesis of endogenous DRD2 cDNA. Splice variants were assayed as described below.

\section{Quantitative mRNA Analysis by Real-Time PCR}

Real-time PCR was performed on cDNA samples on an ABI 7000 sequence detection system with Power SYBR Green PCR Master Mix (Life Technologies). DRD2 expression levels, in arbitrary units, were calculated by subtracting the $\beta$-actin cycle threshold $(\mathrm{Ct})$ from the DRD2 Ct to get a $\Delta \mathrm{Ct}$ as described previously (Pinsonneault et al, 2006). Arbitrary units for each sample $=100\left(2^{-\Delta \mathrm{Ct}}\right)$.

\section{Quantitative Detection of Splice Isoforms}

D2S and D2L were measured following PCR amplification of cDNA with a fluorescent Fam-labeled exon 5 primer and an exon 7 reverse primer as described in Wang et al, 2006. The PCR reaction cycles were stopped in the linear portion of amplification to avoid bias in ratio analyses occurring on saturation of the PCR reaction. Standard curves were 


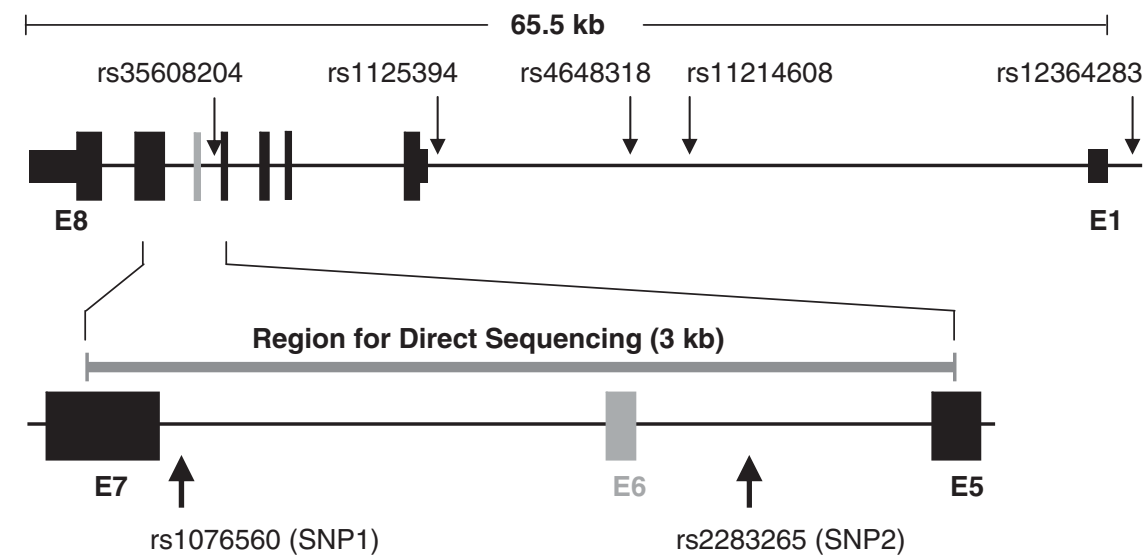

Figure I DRD2 gene map, with blown up view of the region that was sequenced. The exon that is included in D2L but absent in D2S (exon 6) is in gray. The locations of SNPs genotyped in this study are marked.

prepared with varying mixtures of cloned D2S and D2L cDNA (Supplementary Figure 1) (Zhang et al, 2007).

\section{Genotyping Methods}

SNPs were genotyped by at least one of four methods: SNPlex (Life Technologies), SNaPshot (Life Technologies) (Zhang et al, 2005), and allele-specific primers as described in Papp et al, 2003. The fourth method was a modified PCR-restriction fragment length polymorphism method (Haliassos et al, 1989a,b). For this method, one of the PCR primers was Fam-labeled, allowing for resolution of the restriction fragments by capillary electrophoresis with a 3730 DNA analyzer (Life Technologies). SNP1 and SNP2 were genotyped with allele-specific primers and the genotypes confirmed with SNaPshot. Primer sequences are given in Supplementary Table 5.

\section{Statistical Analysis}

HelixTree 6.4.3 (Golden Helix, Bozeman, MT) was used to test for Hardy-Weinberg equilibrium, calculate LD and $R^{2}$ values, haplotype estimation, and a basic allele $\chi^{2}$ test for association with cocaine status. One-way ANOVA and Student's $t$-tests were performed with GraphPad Prism software (GraphPad Software, La Jolla, CA). The associations between genotypes or haplotypes and disease risk as well as the contribution of each minor allele to disease risk were analyzed using logistic regression model performed using SAS 9.1 software (SAS Institute, Cary, NC). The suitability of model fitting was judged by deviance goodness of fit statistics $p$-value and score test $p$-value, both of which should be larger than 0.05 .

\section{RESULTS}

\section{Search for Additional Polymorphisms Associated} with Alternative Splicing

On the basis of results of earlier experiments measuring allelic mRNA ratios of D2S and D2L in human postmortem tissues obtained from the Stanley Medical Research Institute (Zhang et al, 2007), we selected five samples homozygous for the major alleles of SNP1/SNP2 for further analysis. Any difference in the allelic mRNA ratio between D2S and D2L is an indication of a cis-acting factor affecting splicing. Three of the samples had displayed variation in the allelic mRNA ratio of D2S to D2L, suggesting the presence of other variants potentially affecting splicing, while two samples lacking allelic differences served as controls. An approximately $3 \mathrm{~kb}$ region around exon 6 was sequenced (Figure 1), and the results analyzed for additional polymorphisms associated with differential alternative splicing. One control sample was heterozygous for rs 12363125 , which was judged unlikely to affect splicing. One sample with an allelic D2L/ D2S ratio $>1$ was a heterozygous carrier for the minor allele of rs35608204 (C/T genotype), located in intron 5 (Supplementary Table 1), suggesting a possible effect of rs35608204 on D2 splicing. We did not identify any other sequence differences in the samples.

\section{Alternative Splicing of a DRD2 Minigene Carrying rs35608204}

We introduced the minor ' $C$ ' allele SNP of rs35608204 into a partial gene construct containing exon 5 to 7 and carrying the major alleles of SNP1/SNP2 in an expression vector (Zhang et al, 2007). This construct along with two others, one carrying the minor alleles of both SNP1 and SNP2 with the major allele of $\mathrm{rs} 35608204$ and a reference construct carrying the major alleles of all three SNPs, were transfected separately into HEK 293 cells. We extracted RNA from the cells, made cDNA using a plasmid-specific primer, and measured relative expression of D2S and D2L mRNA (cDNA), using PCR with fluorescently labeled primers. As shown previously by Zhang et al, 2007, the minor alleles of SNP1/SNP2 generated significantly less D2S relative to D2L (Figure 2). However, rs35608204 did not affect D2S/L splicing (Figure 2). These results confirm that the minor $\mathrm{T}$ alleles of SNP1/SNP2 reduce the formation of D2S relative to D2L but do not support a role for rs35608204 in D2S/L splicing regulation.

\section{DRD2 mRNA Expression in Human PFC and Putamen from Cocaine Abusers and Controls}

We measured overall DRD2 mRNA expression with realtime PCR in postmortem human PFC and putamen from 


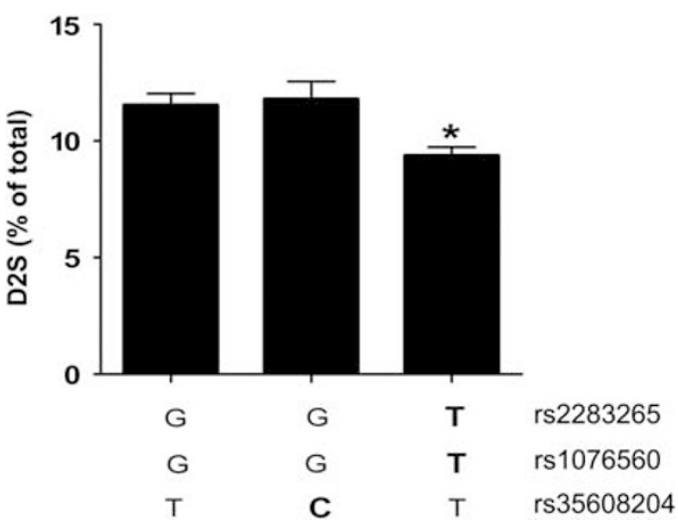

Figure 2 Alternative splicing from DRD2 minigenes in HEK 293 cells. Minigenes carrying the indicated genotypes were transfected into HEK 293 cells and D2S relative to D2L expression levels measured. Minor alleles are indicated by bold type. Data are mean \pm SEM $(n=3$ separate transfections). ${ }^{*} p<0.05$, one-way ANOVA with Bonferroni post test, compared with GGT and GGC.

cocaine abusers and age-matched controls. We did not observe a statistically significant difference in overall $D R D 2$ mRNA expression between cocaine abusers and controls in either brain region in the complete cohort (Figure 3), nor in Caucasians and African Americans when analyzed separately (Supplementary Figure 2). No SNP tested correlated with overall DRD2 mRNA levels (data not shown); any potential small effects would have been masked by large interindividual variability in total mRNA levels in autopsy brain tissues.

\section{Alternative Splicing of DRD2 mRNA in Human PFC and Putamen from Cocaine Abusers and Controls}

To assess D2S/L splicing in the context of cocaine abuse, we measured relative expression of D2S and D2L mRNA in postmortem human PFC and putamen from cocaine abusers and age-matched controls. Consistent with previous reports (Khan et al, 1998; Zhang et al, 2007), relative D2S expression was higher in PFC $(27 \pm 5 \%, n=73)$ than in putamen $(17 \pm 4 \%, n=70)(p<0.0001$, Student's $t$-test $)$. Importantly, subjects carrying the minor allele T of SNP1/ SNP2 had significantly reduced relative expression of D2S mRNA in both brain regions (Figure 4a). This result is consistent with an earlier report (Zhang et al, 2007) and confirms a strong effect of SNP1/SNP2 on D2S/L splicing in both tissues, in a different cohort. Consistent with the results of the in vitro minigene experiments, rs35608204 was not associated with the D2S/L ratio (data not shown). No difference was observed in relative expression of D2S between cocaine abusers and controls in either brain region tested (Figure 4b). As allele frequencies and linkage patterns may differ between populations, we analyzed the relationship of SNP1/SNP2 with D2S/L splicing separately in Caucasians and African Americans and obtained similar results across ethnicity (Supplementary Figure 3), mirroring the combined analysis shown in Figure $4 \mathrm{a}$, and further supporting the role of SNP1/SNP2 as functional variants affecting splicing.
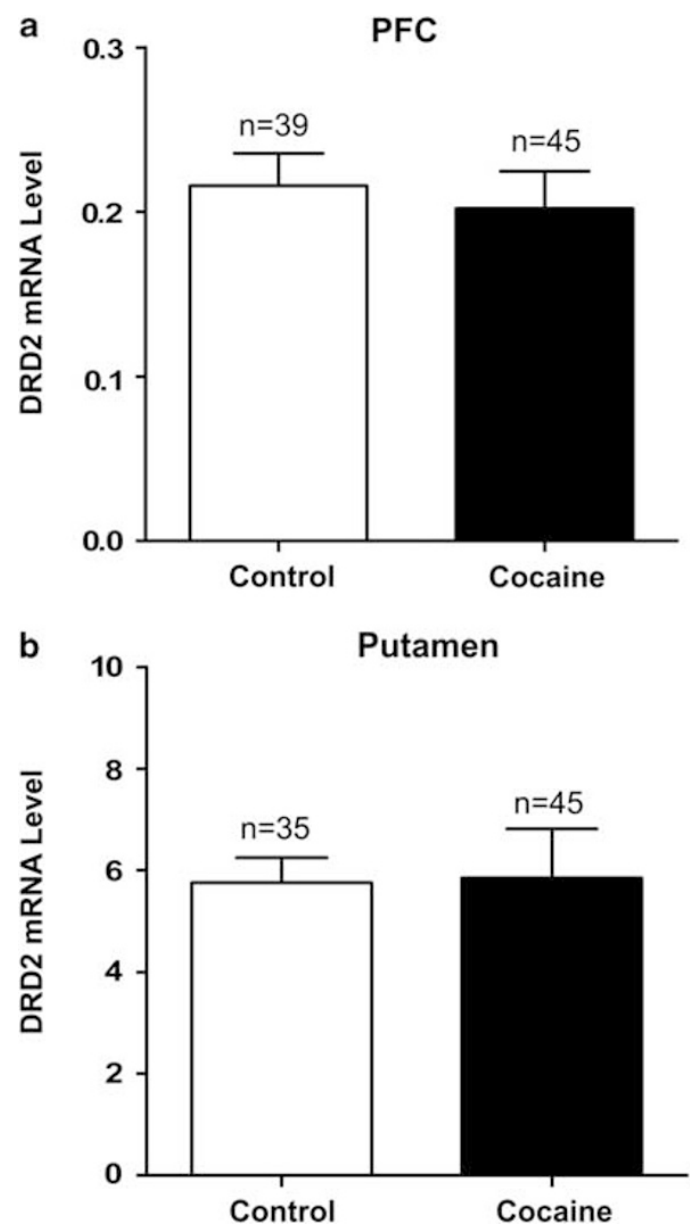

Figure 3 DRD2 mRNA expression in PFC (a) and putamen (b). Realtime PCR was applied to quantify mRNA, with $\beta$-actin as an internal control. DRD2 mRNA levels are presented in arbitrary units (see Materials and methods section). Data are mean \pm SEM, single measurements in PFC and duplicate measurements in putamen.

\section{Cocaine Status and DRD2 Genotype}

Given the well-established role of dopamine signaling in drug addiction and the mounting evidence that SNP1/SNP2 affect the D2S/D2L balance in relevant brain regions, we tested both SNPs for association with cocaine abuse in a population of cocaine abusers $(n=119)$ and age-matched controls $(n=95)$ obtained from an archived biorepository housed in the Miami Brain Endowment Bank (population characteristics are provided in Table 1 and Supplementary Table 2). We also genotyped the SNP we initially suspected might have an effect on D2S/L splicing, rs35608204, as well as the promoter SNP rs12364283, previously shown to alter allelic DRD2 mRNA expression (Zhang et al, 2007) and predictive of avoidance learning in healthy humans (Frank and Hutchison, 2009). In addition, we selected three other DRD2 SNPs for genotyping based on previously reported associations with clinical phenotypes and/or utility as haplotype tagging SNPs: rs1125394 (intron 1, Hwang et al, 2005, 2006), rs4648318 (intron 1, Huang et al, 2009), and rs11214608 ( $5^{\prime}$ upstream). All SNPs tested were in Hardy-Weinberg equilibrium $(p>0.05)$ except SNP1, SNP2, and a third SNP, rs1125394, in high LD with SNP1/SNP2, 

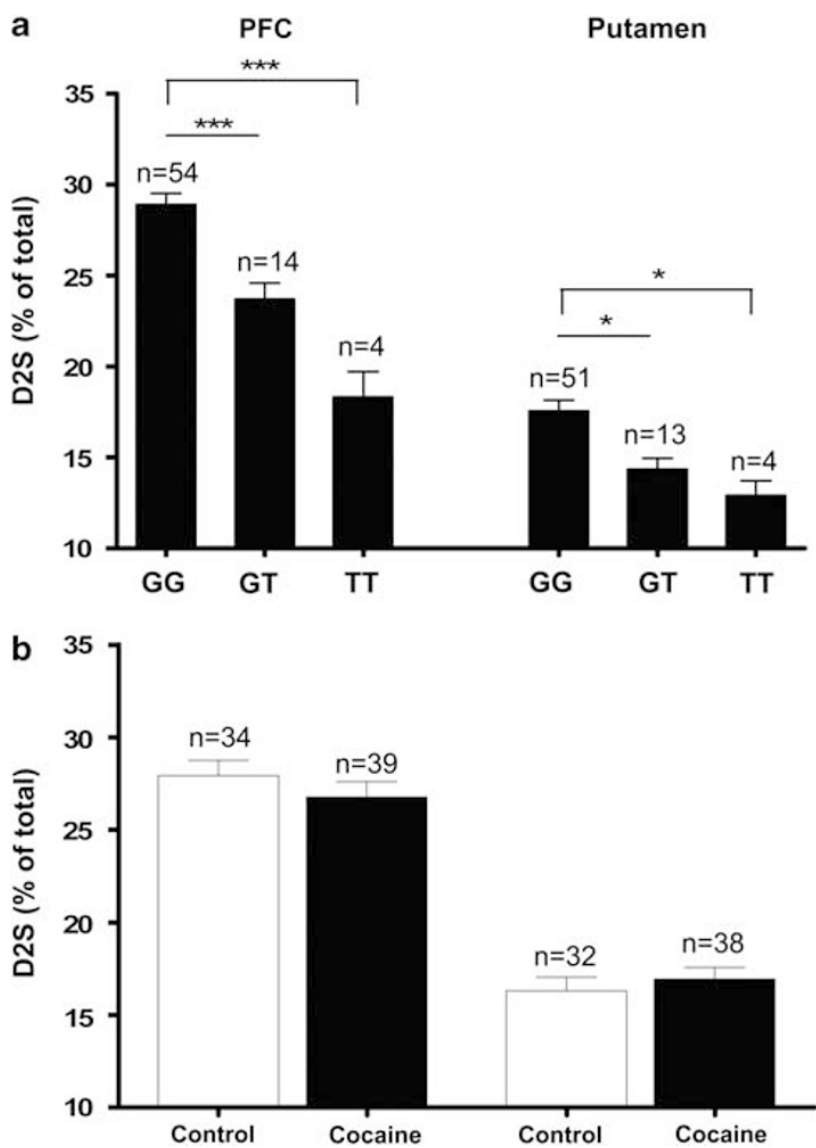

Figure 4 Expression of D2S relative to D2L. (a) Relative D2S mRNA expression grouped by SNPI/SNP2 genotype ( $T$ is minor allele). (b) Relative D2S mRNA expression grouped by cocaine abuse status. Data are mean $\pm \mathrm{SEM}$, at least three measurements per sample, $* 2<0.05$, **** $p<0.00$ I, one-way ANOVA with Bonferroni post test.

$\left(D^{\prime}=1.0\right.$, Supplementary Table 3$)$. The violation of HardyWeinberg equilibrium for SNP1/SNP2 appears to be driven by the cocaine abuse cohort, as all three SNPs were in Hardy-Weinberg equilibrium in the controls. Genotyping errors are unlikely to be the cause, as SNP1 and SNP2 genotypes were verified with two independent methods.

We found that SNP1, SNP2, and rs1125394 were associated with cocaine abuse, with minor allele frequencies approximately twofold higher in cocaine abusers than in controls (SNP2: $p=0.01, \mathrm{OR}=2.3,95 \%$ CI 1.2-4.2, Table 2). When the data were analyzed separately in Caucasians and African Americans, association of SNP1/SNP2 with cocaine abuse was even stronger in Caucasians (SNP2: $p=0.001$, $\mathrm{OR}=3.4,95 \% \mathrm{CI} 1.7-7.1$ ), whereas there was no significant association in African Americans, who have a considerably lower minor allele frequency ( $7 v s 18 \%$ in Caucasians; Table 2). When we analyzed the genotype effect (ie, SNP2 GG, GT, and TT) vs cocaine status, the association did not reach statistical significance in the complete cohort (TT $v s$ $\mathrm{GG}, p=0.06, \mathrm{OR}=7.3,95 \% \mathrm{CI} 0.90-60)$ or was borderline in the Caucasian subgroup (TT $v s \mathrm{GG}, p=0.052, \mathrm{OR}=8.3$, 95\% CI 0.98-70) despite the large odds ratios, possibly because of the relatively small sample size.

To assess the effect of cocaine abuse on D2S/L splicing, we analyzed the splicing data from both brain regions broken
Table I Demographic Characteristics

\begin{tabular}{lcc}
\hline & Controls & Cocaine abusers \\
\hline$n$ & 93 & 118 \\
Age $($ mean \pm SD) & $35 \pm 11$ & $37 \pm 10$ \\
$\%$ Male & $87 \%$ & $85 \%$ \\
Caucasian & 63 & 74 \\
African American & 30 & 44 \\
\hline
\end{tabular}

Three individuals were excluded from all analyses and are not included in this table. One was the only subject of Asian ancestry, and we did not obtain quality DNA/reliable genotyping results from the other two. The postmortem interval of tissue collection (PMI) and $\mathrm{pH}$ of the tissues analyzed for DRD2 splice variants did not differ between controls and cocaine abusers: $17 \pm 5$ and $16 \pm 6 \mathrm{~h}$, respectively, and pH $6.6 \pm 0.2$ and $6.4 \pm 0.3$, respectively. The presence of cocaine and its metabolite benzoylecgonine was verified in both blood and brain tissues of the cocaine abusers, while drug-free controls had also been screened for drugs of abuse.

down by SNP1/SNP2 genotype and further analyzed across controls and cocaine abusers within each group. No significant differences in D2S/L splicing were detectable between controls and cocaine abusers (Supplementary Figure 4).

\section{Haplotype Analysis}

We conducted a haplotype analysis for all seven SNPs and identified four major haplotypes that occurred at $>2 \%$ frequency in the complete cohort (Supplementary Table 4). Of the two haplotypes containing the minor alleles of SNP1/ SNP2, the more frequent haplotype $\mathrm{H} 3$ was present at almost twice the frequency in cocaine abusers $v s$ controls (14 vs 8\%), although the association with cocaine abuse did not reach statistical significance in the complete cohort $(p=0.2)$. The haplotype distribution (Supplementary Table 4) and LD pattern (Supplementary Table 3) differed between Caucasians and African Americans. The frequent haplotype carrying the minor alleles of SNP1/SNP2, H3, was significantly associated with cocaine abuse in Caucasians $(p=0.049, \mathrm{OR}=3.0,95 \%$ CI $1.0-9.1)$. The association of this haplotype was less significant than that of SNP1 or SNP2 alone and is likely fully accounted for by SNP1/SNP2. However, in African Americans the $\mathrm{H} 3$ haplotype was much less frequent, (Supplementary Table 4), with no significant differences observed $(p=0.6)$. No other haplotype was associated with cocaine abuse in the complete cohort or in the Caucasian or African-American subgroups.

\section{DISCUSSION}

This study confirms a robust effect of SNP1/SNP2 on D2S/L splicing in human PFC and putamen autopsy tissues in a cohort of cocaine abusers with a documented history of heavy abuse and age-matched controls. Sequencing the region of $D R D 2$ between exon 5 and 7 failed to reveal any additional candidate SNP affecting D2 splicing. A genetic association analysis revealed that SNP1/SNP2 are strongly associated with cocaine abuse in Caucasians but not African Americans. 
Table 2 Minor Allele Frequencies in Cocaine Abusers and Controls, Plus Results of Statistical Group Comparisons

\begin{tabular}{|c|c|c|c|c|c|}
\hline \multirow{2}{*}{$\begin{array}{l}\text { All }(n=214) \\
\text { SNP }\end{array}$} & \multicolumn{5}{|c|}{ Minor allele frequencies } \\
\hline & All & Controls $(n=95)$ & Cocaine $(n=119)$ & $\chi^{2}, p$-value & Odds ratio $(95 \% \mathrm{Cl})$ \\
\hline rs2283265 (SNP2) & 0.14 & 0.09 & 0.18 & 0.01 & $2.27(1.23-4.19)$ \\
\hline rs35608204 & 0.02 & 0.03 & 0.02 & 0.30 & $0.52(0.14-1.86)$ \\
\hline$r s|12| 4608^{a, b}$ & 0.45 & 0.51 & 0.41 & 0.09 & $0.67(0.42-1.06)$ \\
\hline rs|2364283 & 0.06 & 0.05 & 0.07 & 0.53 & I.3। (0.56-3.07) \\
\hline
\end{tabular}

Caucasians $(n=137)$

Minor allele frequencies

\begin{tabular}{|c|c|c|c|c|c|}
\hline SNP & All & Controls $(n=63)$ & Cocaine $(n=74)$ & $\chi^{2}, p$-value & Odds ratio $(95 \% \mathrm{Cl})$ \\
\hline rs2283265 (SNP2) & 0.18 & 0.09 & 0.25 & 0.001 & $3.42(1.66-7.05)$ \\
\hline $\mathrm{rs} \mid 125394^{\mathrm{a}}$ & 0.17 & 0.09 & 0.25 & 0.004 & $3.33(1.42-7.80)$ \\
\hline rs $4648318^{a}$ & 0.21 & 0.23 & 0.19 & 0.46 & $0.78(0.39-1.53)$ \\
\hline
\end{tabular}

African Americans $(n=76)$

Minor allele frequencies

\begin{tabular}{|c|c|c|c|c|c|}
\hline SNP & All & Controls $(n=3 I)$ & Cocaine $(n=45)$ & $\chi^{2}, p$-value & Odds ratio $(95 \% \mathrm{Cl})$ \\
\hline rs2283265 (SNP2) & 0.07 & 0.08 & 0.06 & 0.53 & $0.66(0.18-2.40)$ \\
\hline rs| $125394^{a}$ & 0.18 & 0.19 & 0.17 & 0.73 & $0.83(0.28-2.4 I)$ \\
\hline$r s 4648318^{a}$ & 0.43 & 0.35 & 0.47 & 0.28 & $1.61(0.68-3.82)$ \\
\hline
\end{tabular}

Minor allele frequencies were determined for all samples $(n=211)$, controls $(n=93)$, and cocaine abusers $(n=118)$ separately within each group. $\chi^{2} p$-values $<0.05$ are in bold type.

${ }^{a}$ Approximately $70 \%$ of samples were successfully genotyped with SNPlex for SNPs annotated with. The rest of the SNPs were successfully genotyped in $>95 \%$ of samples with a number of techniques (see Materials and methods section).

'The minor (less frequent) allele of rs I 1214608 differs between Caucasians and African Americans.

The association of SNP1/SNP2 with decreased expression of D2S relative to D2L in human PFC and putamen is consistent with our earlier report (Zhang et al, 2007), replicating the finding in a separate population with a different pathophysiology. The validation of SNP1/SNP2 as DRD2 variants affecting D2S/D2L splicing is important because only a firm understanding of the molecular genetic effect can guide the interpretation of clinical association studies.

As the importance of dopamine in the pathophysiology of addiction is well established, perturbations in dopamine signaling could impact an individual's response to drugs of abuse and/or risk for addiction. There is ample evidence that D2S and D2L are functionally distinct (Smith et al, 2002; Usiello et al, 2000; Wang et al, 2000; Xu et al, 2002), and alternative splicing of DRD2 to form D2S and D2L represents a regulatory event that could affect dopamine signaling. Consistent with the compelling evidence for the effects of SNP1/SNP2 on D2S/L splicing, SNP1/SNP2 were strongly associated with cocaine abuse in Caucasians. Allele frequencies were substantially higher in the Caucasian cocaine group (SNP1 24\% and SNP2 25\%), compared with the controls (SNP1 10\% and SNP2 9\% $(p=0.003$ and 0.001 , respectively, Table 2). African Americans having considerably lower SNP1/SNP2 allele frequencies $(\mathrm{MAF}=7 \%)$ were insufficiently represented ( $n=74$ vs 137 Caucasians) for testing associations (Table 2). However, the biological effect of SNP1/SNP2 on D2S/L splicing was recapitulated in both groups (Supplementary Figure 3). To determine whether the relative risk of cocaine abuse increase even further for homozygous carriers of SNP1/SNP2, occurring at much lower frequency, a larger study cohort will be needed.

The D2S/L ratio was not measurably correlated with cocaine abuse in our cohort, although SNP1/SNP2 were associated with both reduced relative expression of D2S 
Table 3 Clinical Associations of SNPs in LD $\left(R^{2}>0.6\right)$ with rs 2283265

\begin{tabular}{|c|c|c|c|c|}
\hline $\begin{array}{l}R^{2}(\text { with } \\
\text { rs2283265) }\end{array}$ & SNP & Clinical association & Population & Reference $^{b}$ \\
\hline । & rs2283265 (SNP2) & $\begin{array}{l}\text { Schizophrenia, reduced cognitive } \\
\text { performance, relative avoidance } \\
\text { to reward-seeking behavior }\end{array}$ & $\begin{array}{l}\text { Han Chinese, Caucasian, } \\
\text { Caucasian }\end{array}$ & $\begin{array}{l}\text { Glatt et al, 2009; Zhang et al, } \\
\text { 2007; Frank and Hutchison, } 2009\end{array}$ \\
\hline । & rs 1079594 & $\begin{array}{l}\text { Major allele association with increased alcohol } \\
\text { intake and cigarette smoking }\end{array}$ & Caucasian & Preuss et al, 2007 \\
\hline I & rs2075654 & $\begin{array}{l}\text { Affects working memory performance in the } \\
\text { context of a COMT SNP }\end{array}$ & $\begin{array}{l}\text { Participants in the Netherlands } \\
\text { twin register }\end{array}$ & Gosso et al. 2008 \\
\hline I & rs 1079727 & Schizophrenia & Han Chinese & Glatt et al, 2009 \\
\hline 0.94 & rs 1079596 & $\begin{array}{l}\text { Commission errors on a continuous } \\
\text { performance task test }\end{array}$ & $\begin{array}{l}\text { 79\% Caucasian, } 16 \% \text { African } \\
\text { American }\end{array}$ & Kollins et al, 2008 \\
\hline 0.65 & $\begin{array}{l}\text { rs } \mid 800497 \\
(T a q \mid A)\end{array}$ & $\begin{array}{l}\text { Alcoholism, antipsychotic drug response, drug } \\
\text { addiction, smoking behavior, tardive dyskinesia }\end{array}$ & Mixed & $\begin{array}{l}\text { Munafo et al, 2007; Zhang } \\
\text { et al, 20 I0; Le Foll et al, 2009; } \\
\text { Munafo et al, 2004; } \\
\text { Thelma et al, 2008 }\end{array}$ \\
\hline
\end{tabular}

an HapMap CEU population.

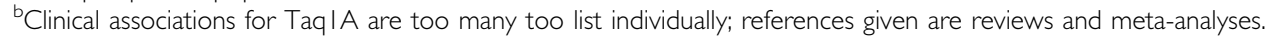

and with cocaine abuse. The influence of external transacting factors on transcription and alternative splicing can introduce sufficient noise so that any relationship between splicing and cocaine abuse is no longer apparent in a small cohort. Also, from this study alone we cannot exclude the possibility that cocaine exposure affects D2 splicing in specific brain regions or neurons not analyzed or accessible here. Previous evidence supports extensive trans effects on splicing. Cocaine abuse has been shown to act as a trans-factor modulating overall gene expression in humans and animals (reviewed in Lull et al, 2008) and altering differential expression of specific isoforms of brain-derived neurotrophic factor in human brain (Jiang et al, 2009). Furthermore, D2S and D2L expression in mouse striatum and ventral tegmental area is differentially affected following treatment with amphetamine, another psychostimulant (Giordano et al, 2006). A host of other trans-acting factors, including postmortem decay and RNA isolation from postmortem human tissues could have contributed to increased variability in the measurements of D2S/L splicing, confounding the three-way relationship between genotype, splicing, and cocaine abuse. Further studies are needed to characterize the interaction between SNP1/SNP2 genotype, cocaine abuse, and D2S/L splicing.
Numerous previous studies had implicated several DRD2 variants as risk factors in a spectrum of clinical traits (Table 3); however, clinical associations per se are often not replicated leading to low acceptance of such results. We therefore addressed the question whether some of these candidate SNPs are in LD with SNP1/SNP2, and hence could be considered surrogate markers. A number of SNPs in high LD with SNP1/SNP2 form a large haplotype block (Figure 5) (http://www.broadinstitute.org/mpg/snap/ldplot.php; Johnson et al, 2008). For example, a SNP tested in this study, rs1125394, in tight LD with SNP1/SNP2 $\left(D^{\prime}=1.0\right.$, Supplementary Table 3 ), had been similarly associated with cocaine abuse (Table 2). This same SNP had also been shown to predict clozapine response in schizophrenic patients (Hwang et al, 2005, 2006). With $R^{2}$ values near 1.0 for several SNPs in the SNP1/SNP2 haplotype block, we can consider these findings (Table 3) to represent independent validation of pervasive clinical relevance. All of these variants can thus be considered markers for a true genetic effect with demonstrable impact on human behavioral phenotypes (Table 3 ). It is further noted that the LD block extends into the adjacent gene ANNK1 (Figure 5), including the Taq1A variant used as a marker in numerous clinical association studies (Table 3). Although ANNK1 


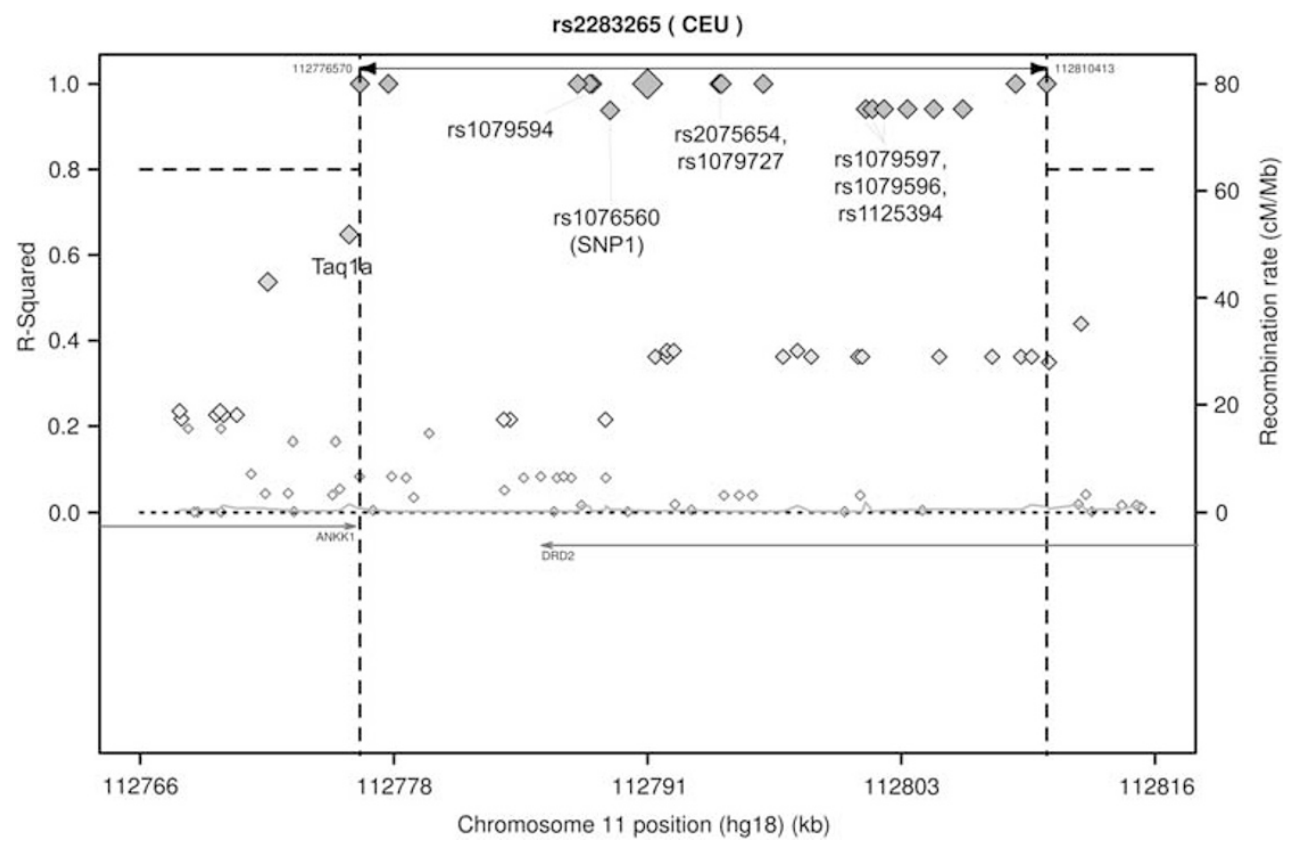

Figure 5 LD plot of surrogate markers for the intron 5 SNP rs2283265 (SNP2) as the seed (http://www.broadinstitute.org/mpg/snap/ldplot.php) (Johnson et al, 2008). The sequence window spans $25 \mathrm{~kb}$ on either side of the seed SNP, overlapping with both the DRD2 and ANNKI genes (arrows reflecting gene orientation), and the threshold was set at $r^{2}=0.8$. The recombination rate (not shown) is low throughout the entire region with high $\mathrm{LD}$ but increases strongly at the borders. The LD results are from the CEU population (Utah residents with ancestry from northern and western Europe; HapMap release 22, Frazer et al, 2007). In Yoruban subjects in Ibadan, Nigeria (YRI), a significantly shortened LD block was observed, not extending beyond the DRD2 locus (not shown).

could well represent a risk gene on its own, the strong LD to SNP1/SNP2 in the DRD2 locus must be considered. Finally, the haplotype block is significantly shorter in subjects of African descent when measured using the Yoruban HapMap population (not shown), indicating that strong ethnic differences in association studies can be expected.

Additional contributions must also be considered for other proposed functional $D R D 2$ variants not in high LD with SNP1/SNP2. Candidate variants in the DRD2 gene locus with clinical associations and in vitro evidence for being functional include rs 12364283 (Frank and Hutchison, 2009, Zhang et al, 2007), rs6277 (C957T; Duan et al, 2003; Lawford et al, 2005; Voisey et al, 2009; Zai et al, 2007), and rs1799732 (-141C Ins/Del; Arinami et al, 1997; Ishiguro et al, 1998; Lerman et al, 2006). Any possible contributions from these SNPs cannot be ruled out here; however, our previous results on allelic mRNA expression in putamen and PFC had failed to support a detectable functional effect of rs6277 (thought to alter mRNA turnover) or rs 1799732 (transcription) in these brain tissues (Zhang et al, 2007).

In summary, we have examined the relationship between DRD2 genotype, D2S/L splicing, and cocaine abuse. The results support a robust effect of SNP1/SNP2 decreasing the relative expression of D2S in human brain as reported previously (Zhang et al, 2007). Moreover, the minor alleles of SNP1/SNP2 represent apparent strong risk factors in cocaine overdose cases. Clinical penetrance is supported by numerous earlier clinical association results in various disorders with these same SNPs, or surrogate SNPs in high LD with them. Taking all previous studies and the present results together, these two splice SNPs modulate dopamine signaling in human brain, affecting cognitive processes and psychiatric disorders including drug addiction, and response to therapies. The large odds ratios observed for SNP1/SNP2 in the present study for risk of cocaine abuse indicates a large effect size in this population of subjects with documented heavy abuse, leading eventually to cocaine overdose and death.

\section{ACKNOWLEDGEMENTS}

DNA extracted from postmortem brain tissues used for the sequencing experiments was donated by The Stanley Medical Research Institute's brain collection, courtesy of Dr Maree Webster. We thank Gloria Smith and Amanda Zaret for technical assistance. This work was supported by National Institute of Health Research Grants R01 DA022199 and U01 GM092655.

\section{DISCLOSURE}

The authors declare no conflict of interest.

\section{REFERENCES}

Arinami T, Gao M, Hamaguchi H, Toru M (1997). A functional polymorphism in the promoter region of the dopamine D2 receptor gene is associated with schizophrenia. Hum Mol Genet 6: 577-582.

Bertolino A, Fazio L, Di Giorgio A, Blasi G, Romano R, Taurisano P et al (2009a). Genetically determined interaction between the dopamine transporter and the D-2 receptor on prefronto-striatal activity and volume in humans. J Neurosci 29: 1224-1234. 
Bertolino A, Fazio L, Caforio G, Blasi G, Rampino A, Romano R et al (2009b). Functional variants of the dopamine receptor D2 gene modulate prefronto-striatal phenotypes in schizophrenia. Brain 132: 417-425.

Bertolino A, Taurisano P, Pisciotta NM, Blasi G, Fazio L, Romano $\mathrm{R}$ et al (2010). Genetically determined measures of striatal D2 signaling predict prefrontal activity during working memory performance. Plos One 5(2): e9348.

Blasi G, Lo Bianco L, Taurisano P, Gelao B, Romano R, Fazio L et al (2009). Functional variation of the dopamine D-2 receptor gene is associated with emotional control as well as brain activity and connectivity during emotion processing in humans. J Neurosci 29: 14812-14819.

Civelli O, Bunzow JR, Grandy DK (1993). Molecular diversity of the dopamine receptors. Ann Rev Pharmacol Toxicol 33: 281-307.

Doehring A, von Hentig N, Graff J, Salamat S, Schmidt M, Geisslinger $\mathrm{G}$ et al (2009). Genetic variants altering dopamine D2 receptor expression or function modulate the risk of opiate addiction and the dosage requirements of methadone substitution. Pharmacogenetics Genomics 19: 407-414.

Duan JB, Wainwright MS, Comeron JM, Saitou N, Sanders AR, Gelernter J et al (2003). Synonymous mutations in the human dopamine receptor D2 (DRD2) affect mRNA stability and synthesis of the receptor. Hum Mol Genet 12: 205-216.

Frank MJ, Hutchison K (2009). Genetic contributions to avoidance-based decisions: striatal D2 receptor polymorphisms. Neuroscience 164: 131-140.

Frazer KA, Ballinger DG, Cox DR, Hinds DA, Stuve LL, Gibbs RA et al (2007). A second generation human haplotype map of over 3.1 million SNPs. Nature 449: 851-U853.

Giordano TP, Satpute SS, Striessnig J, Kosofsky BE, Rajadhyaksha AM (2006). Up-regulation of dopamine D2L mRNA levels in the ventral tegmental area and dorsal striatum of amphetaminesensitized C57BL/6 mice: role of $\mathrm{Ca}(\mathrm{v}) 1.3$ L-type Ca2+ channels. J Neurochem 99: 1197-1206.

Glatt SJ, Faraone SV, Lasky-Su JA, Kanazawa T, Hwu HG, Tsuang MT (2009). Family-based association testing strongly implicates $D R D 2$ as a risk gene for schizophrenia in Han Chinese from Taiwan. Mol Psychiatry 14: 885-893.

Gosso MF, de Geus EJC, Polderman TJC, Boomsma DI, Heutink P, Posthuma D (2008). Catechol O-methyl transferase and dopamine D2 receptor gene polymorphisms: evidence of positive heterosis and gene-gene interaction on working memory functioning. Eur J Hum Genet 16: 1075-1082.

Haliassos A, Chomel JC, Grandjouan S, Kruh J, Kaplan JC, Kitzis A (1989a). Detection of minority point mutations by modified PCR technique - a new approach for a sensitive diagnosis of tumorprogression markers. Nucleic Acids Res 17: 8093-8099.

Haliassos A, Chomel JC, Tesson L, Baudis M, Kruh J, Kaplan JC et al (1989b). Modification of enzymatically amplified DNA for the detection of point mutations. Nucleic Acids Res 17: 3606-3606.

Herzberg I, Valencia-Duarte AV, Kay VA, White DJ, Muller H, Rivas IC et al (2010). Association of DRD2 variants and Gilles de la Tourette syndrome in a family-based sample from a South American population isolate. Psychiatr Genet 20: 179-183.

Huang WH, Payne TJ, Ma JZ, Beuten J, Dupont RT, Inohara N et al (2009). Significant association of ANKK1 and detection of a functional polymorphism with nicotine dependence in an AfricanAmerican sample. Neuropsychopharmacology 34: 319-330.

Hwang R, Shinkai T, De Luca V, Muller DJ, Ni XQ, Macciardi F et al (2005). Association study of 12 polymorphisms spanning the dopamine D-2 receptor gene and clozapine treatment response in two treatment refractory/intolerant populations. Psychopharmacology 181: 179-187.

Hwang R, Shinkai T, Deluca V, Macciardi F, Potkin S, Meltzer HY et al (2006). Dopamine D2 receptor gene variants and quantitative measures of positive and negative symptom response following clozapine treatment. Eur Neuropsychopharmacol 16: 248-259.

Hyman SE, Malenka RC, Nestler EJ (2006). Neural mechanisms of addiction: the role of reward-related learning and memory. Ann Rev Neurosci 29: 565-598.

Ishiguro H, Arinami T, Saito T, Akazawa S, Enomoto M, Mitushio $\mathrm{H}$ et al (1998). Association study between the -141C Ins/Del and TaqI A polymorphisms of the dopamine D2 receptor gene and alcoholism. Alcohol Clin Exp Res 22: 845-848.

Jiang XY, Zhou J, Mash DC, Marini AM, Lipsky RH (2009). Human BDNF isoforms are differentially expressed in cocaine addicts and are sorted to the regulated secretory pathway independent of the Met66 substitution. Neuromol Med 11: 1-12.

Johnson AD, Wang DX, Sadee W (2005). Polymorphisms affecting gene regulation and mRNA processing: broad implications for pharmacogenetics. Pharmacol Ther 106: 19-38.

Johnson AD, Handsaker RE, Pulit SL, Nizzari MM, O’Donnell CJ, de Bakker PIW (2008). SNAP: a web-based tool for identification and annotation of proxy SNPs using HapMap. Bioinformatics 24: 2938-2939.

Khan ZU, Mrzljak L, Gutierrez A, de la Calle A, Goldman-Rakic PS (1998). Prominence of the dopamine D2 short isoform in dopaminergic pathways. Proc Natl Acad Sci USA 95: 7731-7736.

Kollins SH, Anastopoulos AD, Lachiewicz AM, FitzGerald D, Morrissey-Kane E, Garrett ME et al (2008). SNPs in dopamine D2 receptor gene (DRD2) and norepinephrine transporter gene (NET) are associated with continuous performance task (CPT) phenotypes in ADHD children and their families. Am J Med Genet BNeuropsychiatr Genet 147B: 1580-1588.

Lawford BR, Young RM, Swagell CD, Barnes M, Burton SC, Ward WK et al (2005). The C/C genotype of the C957T polymorphism of the dopamine D2 receptor is associated with schizophrenia. Schizophr Res 73: 31-37.

Le Foll B, Gallo A, Le Strat Y, Lu L, Gorwood P (2009). Genetics of dopamine receptors and drug addiction: a comprehensive review. Behav Pharmacol 20: 1-17.

Lerman C, Jepson C, Wileyto EP, Epstein LH, Rukstalis M, Patterson F et al (2006). Role of functional genetic variation in the dopamine $\mathrm{D} 2$ receptor (DRD2) in response to bupropion and nicotine replacement therapy for tobacco dependence: results of two randomized clinical trials. Neuropsychopharmacology 31: 231-242.

Lucht M, Samochowiec A, Samochowiec J, Jasiewicz A, Grabe HJ, Geissler I et al (2010). Influence of DRD2 and ANKK1 genotypes on apomorphine-induced growth hormone (GH) response in alcohol-dependent patients. Prog Neuro-Psychopharmacol Biol Psychiatry 34: 45-49.

Lull ME, Freeman WM, Vrana KE, Mash DC (2008). Correlating human and animal studies of cocaine abuse and gene expression. Addiction Rev 1141: 58-75.

Munafo MR, Clark TG, Johnstone EC, Murphy MFG, Walton RT (2004). The genetic basis for smoking behavior: a systematic review and meta-analysis. Nicotine Tobacco Res 6: 583-597.

Munafo MR, Matheson IJ, Flint J (2007). Association of the DRD2 gene Taq1A polymorphism and alcoholism: a meta-analysis of case-control studies and evidence of publication bias. Mol Psychiatry 12: 454-461.

Papp AC, Pinsonneault JK, Cooke G, Sadee W (2003). Single nucleotide polymorphism genotyping using allele-specific PCR and fluorescence melting curves. Biotechniques 34: 1068-1072.

Pinsonneault JK, Papp AC, Sadee W (2006). Allelic mRNA expression of X-linked monoamine oxidase a $(M A O A)$ in human brain: dissection of epigenetic and genetic factors. Hum $\mathrm{Mol}$ Genet 15: 2636-2649.

Preuss UW, Zill P, Koller G, Bondy B, Soyka M (2007). D2 dopamine receptor gene haplotypes and their influence on alcohol and tobacco consumption magnitude in alcoholdependent individuals. Alcohol Alcohol 42: 258-266. 
Rockman MV, Wray GA (2002). Abundant raw material for cis-regulatory evolution in humans. Mol Biol Evol 19: 1991-2004.

Sasabe T, Furukawa A, Matsusita S, Higuchi S, Ishiura S (2007). Association analysis of the dopamine receptor D2 (DRD2) SNP rs 1076560 in alcoholic patients. Neurosci Lett 412: 139-142.

Seamans JK, Yang CR (2004). The principal features and mechanisms of dopamine modulation in the prefrontal cortex. Prog Neurobiol 74: 1-57.

Smith JW, Fetsko LA, Xu R, Wang Y (2002). Dopamine D2L receptor knockout mice display deficits in positive and negative reinforcing properties of morphine and in avoidance learning. Neuroscience 113: 755-765.

Strange PG (1993). New insights into dopamine-receptors in the central nervous system. Neurochem Int 22: 223-236.

Thelma BK, Srivastava V, Tiwari AK (2008). Genetic underpinnings of tardive dyskinesia: passing the baton to pharmacogenetics. Pharmacogenomics 9: 1285-1306.

Usiello A, Baik JH, Rouge-Pont F, Picetti R, Dierich A, LeMeur M et al (2000). Distinct functions of the two isoforms of dopamine D-2 receptors. Nature 408: 199-203.

Voisey J, Swagell CD, Hughes IP, Alorris CP, van Daal A, Noble EP et al (2009). The DRD2 gene $957 \mathrm{C}>\mathrm{T}$ polymorphism is associated with posttraumatic stress disorder in war veterans. Depress Anxiety 26: 28-33.

Volkow ND, Fowler JS, Wang GJ, Hitzemann R, Logan J, Schlyer DJ et al (1993). Decreased dopamine-D2 receptor availability is associated with reduced frontal metabolism in cocaine abusers. Synapse 14: 169-177.
Wang D, Papp AC, Binkley PF, Johnson JA, Sadee W (2006). Highly variable mRNA expression and splicing of L-type voltagedependent calcium channel alpha subunit 1C in human heart tissues. Pharmacogenetics Genomics 16: 735-745.

Wang YY, Xu R, Sasaoka T, Tonegawa S, Kung MP, Sankoorikal EB (2000). Dopamine D2 long receptor-deficient mice display alterations in striatum-dependent functions. J Neurosci 20: 8305-8314.

Wray GA (2007). The evolutionary significance of cis-regulatory mutations. Nat Rev Genet 8: 206-216.

Xu R, Hranilovic D, Fetsko LA, Bucan M, Wang Y (2002). Dopamine D2S and D2L receptors may differentially contribute to the actions of antipsychotic and psychotic agents in mice. Mol Psychiatry 7: 1075-1082.

Zai CC, Hwang RW, De Luca V, Muller DJ, King N, Zai GC et al (2007). Association study of tardive dyskinesia and twelve DRD2 polymorphisms in schizophrenia patients. Int J Neuropsychopharmacol 10: 639-651.

Zhang JP, Lencz T, Malhotra AK (2010). D-2 receptor genetic variation and clinical response to antipsychotic drug treatment: a meta-analysis. Am J Psychiatry 167: 763-772.

Zhang Y, Bertolino A, Fazio L, Blasi G, Rampino A, Romano R et al (2007). Polymorphisms in human dopamine D2 receptor gene affect gene expression, splicing, and neuronal activity during working memory. Proc Natl Acad Sci USA 104: 20552-20557.

Zhang Y, Wang DX, Johnson AD, Papp AC, Sadee W (2005). Allelic expression imbalance of human mu opioid receptor (OPRM1) caused by variant A118G. J Biol Chem 280: 32618-32624.

Supplementary Information accompanies the paper on the Neuropsychopharmacology website (http://www.nature.com/npp) 